Faculdade de Ciências Econômicas UFRGS
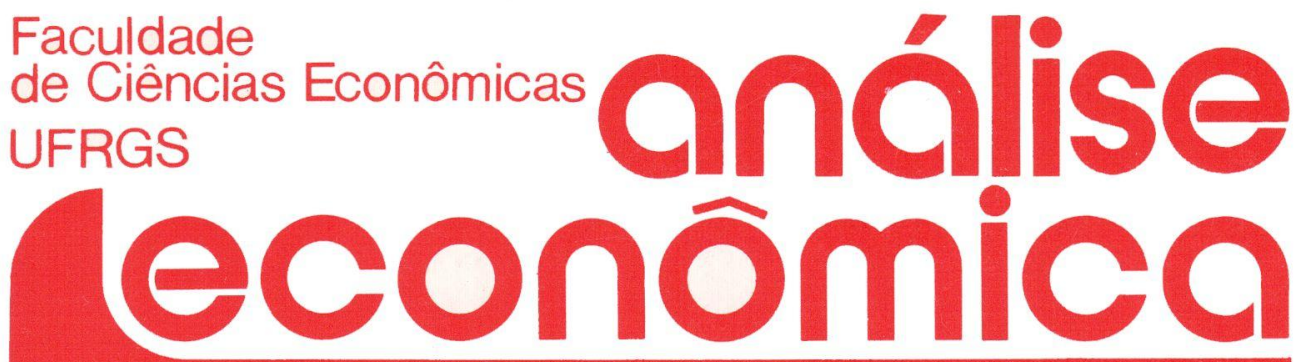

nesta edição:

- PRODUÇÃO DE ÁLCOOL E EMPREGO Otto G. Konzen e Juvir L. Mattuella

- NECESSIDADE DE PENSAR E CONSTRUIR O PÓS-CRISE Marcus Vinicius Pratini de Moraes

- CONTAS EXTERNAS

Fernando Ferrari Filho

- FETICHISMO

Leda Maria Paulani

- CRISE DO CAPITALISMO MUNDIAL Beki Morón de Macadar

- EXPANSÃO CAFEEIRA NO ESPÍRITO SANTO José L. Celin
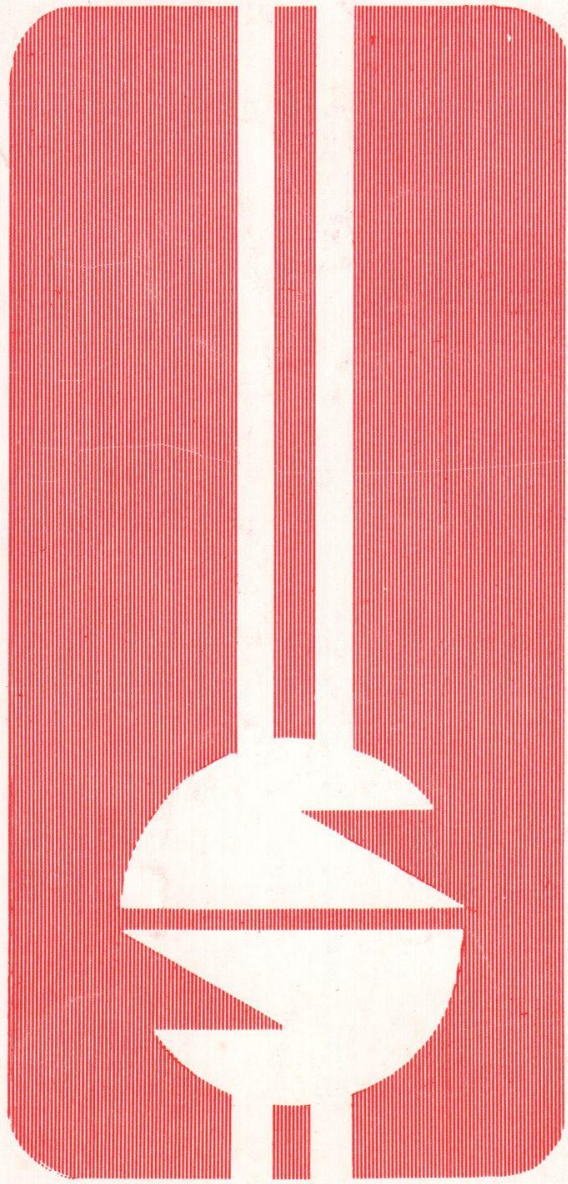
DIRETOR DA FACULDADE DE CIÉNCIAS ECONOMMICAS:

Prof. Antonio Carlos Santos Rosa/Prof. Edgar Irio Simm

VICE-DIRETOR:Prof. Nelson Rokembach/Prof. Walter Meucci Nique

CHEFE DO DEPARTAMENTO DE CIẼNCIAS ECONÔMICAS:

Prof. Renato Batista Masina

CONSElHo EdITORIAL: Prof. Pedro Cezar Dutra Fonseca (Presidente)

Prof. Achyles Barcelos da Costa

Prof. Carlos Augusto Crusius

Prof. Claudio Francisco Accurso

Prof. Edgar Augusto Lanzer

Prof. Ernani Hickmann

Prof. Nali de Jesus de Souza

Prof. Nuno Renan Lu de Figueiredo Pinto

Profa Otilia Beatriz Kroeff Carrion

Prof. Roberto Camps Moraes

Profạ Yeda Rorato Crusius

FUNDADOR: Prof. Antonio Carlos Santos Rosa

ANALISE ECONÔMICA publica dois números anuais, nos meses de março e novembro. O preço da așsinatura para 1985 é $\mathrm{Cr} \$ 6.000,00$, a ser pago através de cheque nominal para "Faculdade de Ciências Econômicas - UFRGS". Aceita-se permuta com revistas congêneres. Aceitam-se, também, livros para elaboração de resenhas ou recensões.

Toda a correspondência, material para publicação, assinaturas e permutas devem ser dirigidas a:

Prof. PEDRO CEZAR DUTRA FONSECA

Revista Análise Econômica

Avenida João Pessoa, $52-3 \%$ andar

90.000 - Porto Alegre (RS) - Brasil 


\title{
CONTRIBUIÇÃO AO ESTUDO DA PEQUENA PRODUÇÃO NA CAFEICULTURA BRASILEIRA - O Caso do Espírito Santo*
}

\author{
J. L. CELIN**
}

\section{1 - INTRODUC̣ĀO}

Este estudo poderia, num primeiro momento, ser caracterizado como um estudo regional apenas por se tratar de uma questão aparentemente sem qualquer importância na história econômica do País. No entanto, é a partir do estudo das regiões brasileiras, no que têm de específico cada uma delas, que desponta uma oportunidade inédita para o entendimento global da realidade brasileira.

No que se relaciona ao Espírito Santo, em que pese o pouco dinamismo da economia local, o "café de Vitória" era, já no início deste século, um produto de cotação internacional, com significativa participação no total da produção brasileira. O objetivo aqui é exatamente o de contribuir para o entendimento desta área específica a partir de suas características próprias e suas inter-relações com o centro dinâmico da economia brasileira. O que se busca, então, é encarar o estudo regional com um espaço para o capital que a partir do centro dominante torna possível a incorporação

\footnotetext{
* Este artigo é uma versão reduzida de um trabalho maior desenvolvido anteriormente: Migração europeia, expansão cafeeira e o nascimento da pequena propriedade no Espirito Santo, apresentado como Dissertação de Mestrado junto ao Curso de Pós-Graduação em Economia do IEPE/UFRGS em 1984.

** Professor do Departamento de Ciências Econômicas, Administrativas e Contábeis da Fundação Universidade do Rio Grande.
}

ANÁLISE ECONOOMICA

ANO 2

No 4

NOV./1984

p. $67-75$ 
econômica das diversas regiões do País, subordinando-as, tornando-as simples economias complementares.

Sem pretender cumprir tarefa tão qualificada, propõe-se, nos limites deste texto, questionar o saber dominante na historiografia sobre o modo de produção na cafeicultura brasileira. Tal propósito será perseguido ao se reconstituir a gênese do café no Estado do Espírito Santo, importante ramal desta cultura no Brasil. Ali, ao contrário do que diz a historiografia, o café se mostrou viável em pequenas propriedades apoiadas basicamente no trabalho familiar. Pode-se afirmar que no Espírito Santo o café possui seus contornos próprios, consolidados nas três primeiras décadas deste século.

\section{2 - ANTECEDENTES DO CAFE NO ESPIRITO SANTO}

Até meados do século passado, a Província do Espírito Santo era quase que inteiramente uma reserva florestal. Alguns naturalistas e viajantes estrangeiros que ali estiveram, como Saint-Hilaire, não se continham ao ver a exuberância da vegetação. ${ }^{1}$ Por que esta província permanecia inexplorada e pouco habitada, contraditoriamente, pode ser explicado pela sua própria localização no Brasil. Próxima à capital do Império e sendo também o litoral mais próximo das minas gerais, possuindo condições de porto muito adequadas, esse trecho da costa brasileira era alvo freqüente das pretensões estrangeiras. Assim, enquanto durou a exploração aurífera, a Vila da Vitória se transformou num obstáculo natural às minas, com fortificações e efetivo militar mantidos pelo Governo Central, além de proibidas a navegação pelo rio Doce e a abertura de estradas em direção oeste.

Chegado o século $X I X$, a economia local se reduzia a uma diminuta produção do açúcar nas imediações de Vitória e no litoral sul, além da pesca para autoconsumo. Apenas no norte, na foz do rio Cricaré (hoje São Mateus), operava-se algo de relativa importância: a produção da farinha de mandioca. No entanto, essa localidade se achava na zona comercial mais diretamente ligada à Bahia, mantendo-se isolada da capital e das demais localidades da Província.

Foram precisos mais de três séculos para se romper com o isolamento. Não obstante, a inserção tardia dessa Província na economia brasileira seria compensada pela abundância relativa de dois

1 - ROCHA, Levy. Viajantes estrangeiros no Espirito Santo. Brasília, Ebasa, 1971. 
fatores essenciais ao café: terra e mão-de-obra. Quanto à mão-deobra, torna-se especialmente importante o fluxo de imigrantes europeus chegados à Província a partir de 1847. Esse fenômeno será analisado nos próximos parágrafos.

\section{3 - DO LATIFUNDIO MERCANTIL-ESCRAVISTA À PEQUENA PRODUC̣ÃO FAMILIAR}

O café, cultivado inicialmente nas imediações da cidade do Rio de Janeiro, rapidamente se espalha por todo o vale do Paraíba, consolidando-se, por volta de 1830, como o principal produto de exportação. O alargamento da produção no Brasil coincide com uma razoável difusão do consumo a nível mundial, o que permitiu o incremento continuado da produção até fins do século passado, quando surgem os primeiros sinais de crise.

A extraordinária expansão ocorrida no século $X I X$ só foi possível em face da existência de terras disponíveis em abundância, clima e solo favoráveis na região sudeste do Brasil. Cabe salientar que o alargamento da fronteira agrícola é condição fundamental à expansão da cafeicultura, uma atividade essencialmente em movimento. ${ }^{2}$ A lavoura em expansão compreendia, pois, três momentos: uma faixa ou zona pioneira, onde o café está penetrando; uma região em que ele se encontra consolidado e plenamente produtivo; e uma região decadente, onde a cultura se encontra em regressão.

Esgotadas as possibilidades das primeiras zonas de plantio a marcha do café atingiria o Espírito Santo em sua direção ao norte. Com a introdução do café no sul da Província, criou-se um poderoso incentivo à migração de fazendeiros mineiros e fluminenses, principalmente nos vales dos rios Itapemirim e Itabapoana. Foi a região do Itapemirim aquela que majoritariamente desenvolveu uma economia tipo plantation escravista, como o demonstrou, em magnífica análise, Ferreira de Almada. ${ }^{3}$ De acordo com esta autora, a economia cafeeira se implantou e se desenvolveu dentro dos moldes escravistas, herança trazida pelos fazendeiros que chegaram à Província. É notável que a população escrava viria a aumentar exatamente depois de extinto o tráfico de negros africanos, os

2 - CASTRO, Antônio Barros de. Café: auge. "sobrevida" e superação. In —. 7 ensaios de economia brasileira. Rio de Janeiro, Forense, 1971. Vol. 2, p. 61.

3 - A escravidão na história econômico-social do Espírito Santo - 1850/1888. Niterói, UFF, 1981. Dissert. Mestr. História, 240 p. 
quais viriam a se constituir no "(...) sustentáculo da economia da Província até 1888'.4

Todavia, um fenômeno contemporâneo ao da escravidão, ausente da análise de Ferreira de Almada, relaciona-se ao movimento que, mesmo no seio da economia escravista, vinha se formando e que, afinal, viria a se tornar a grande causa da expansão do café no Espírito Santo: a colonização por pequenos lotes doados pelo governo.

A repartição das terras devolutas e sua posterior distribuição destinou-se exclusivamente a imigrantes europeus chegados àquela Província. A primeira colônia - Santa Isabel - data de 1847. Tempos depois seriam fundadas Santa Leopoldina (1857) e Santa Teresa (1874); as duas primeiras constituídas de alemães, esta última, por italianos. Além destas, funda-se também a Colônia do Rio Novo (1855), nascida da iniciativa privada. Esta questão está impregnada de controvérsias que foram apontadas, em parte, no trabalho de dissertação sobre o tema. É em decorrência da polêmica criada pela questão imigratória que este movimento só será retomado na última década do século. Com os contingentes chega. dos na década de 1890 - o fluxo imigratório é paralisado definitivamente em 1895 - a imigração estrangeira para o Espírito Santo é estimada em 100 mil indivíduos: cerca de 80 mil italianos e 20 mil alemães e outras nacionalidades.

Em termos absolutos o contingente não é muito grande, tendo em vista que o País recebeu cerca de um milhão e meio de italianos e cerca de 215 mil alemães até $1933 .^{5}$ Se se consideram, porém, os estreitos limites geográficos onde se localizaram estas populações - o Espírito Santo ocupa aproximadamente 0,5\% do território brasileiro - além do alto crescimento vegetativo apresentado, a imigração estrangeira no Espírito Santo é certamente o fato mais relevante ocorrido em sua história. De $80 \mathrm{mil}$ habitantes em 1872, a população estadual passa a ser de $600 \mathrm{mil}$ habitantes em 1930, apresentando freqüentemente taxas de crescimento superiores a $4 \%$ a.a. Em 1900, $16 \%$ da sua população eram estrangeiros. No Estado de São Paulo, que recebeu o maior número de imigrantes, esta proporção era de $23 \%$, no Paraná, $14 \%$ e no Rio Grande do Sul, $12 \%^{-6}$ Releva notar que os contingentes estrangeiros estabelecidos no Espírito Santo se dirigiram exclusivamente aos nú-

4- FERREIRA DE ALMADA, V.P. Op. cit., p. 87.
5 - IBGE, Anuário Estatístico do Brasil, Ano V., 1939/1940, p. 1307.
6 - Ib., p. 1302. 
cleos coloniais. Ainda em 1900, $83 \%$ da população local se dedicavam a atividades agrícolas, enquanto em São Paulo, por exemplo, a percentagem de agricultores era de $64 \%$ e no Rio Grande do Sul, de $66 \%{ }^{7}$

A forma de assentamento dos imigrantes obedecia freqüentemente à apropriação de pequenas áreas. No início, os lotes distribuídos pelo governo possuíam aproximadamente 50 hectares. Depois, foram reduzidos, até se estabelecerem, por fim, em torno de 25 hectares, superfície que passou a ser conhecida como uma "colônia". Algumas famílias, pelos mais variados processos de transferência, se apossaram de várias colônias. Porém, a média, constatou Wagemann no início do século, era de 2 a 3 colônias, ou seja, de 50 a 75 hectares por família. ${ }^{8}$ Esse foi mais ou menos o limite em torno do qual foram se fixando as propriedades. ${ }^{9}$

Pelo Censo de 1920, 89\% dos estabelecimentos recenseados possuíam até 100 hectares. Se se dobrasse a área - até 200 ha seria incorporada a esta categoria quase a totalidade dos estabelecimentos, $96 \%,{ }^{10}$ ocupando $2 / 3$ da área total recenseada. Passados 25 anos do fim da imigração, 17,5\% das propriedades pertenciam ainda a italianos e alemães.

Outros indicadores vêm reforçar a importância da pequena propriedade como unidade produtiva fundamental. Por exemplo, os índices de absenteísmo são insignificantes, exatamente por ser o proprietário o responsável direto pela exploração do sítio, o que ocorre em $94 \%$ dos casos. Administradores e arrendatários são categorias pouco presentes. ${ }^{11} \mathrm{O}$ caráter familiar dos empreendimentos torna-os independentes. Aí se produz, além do café, praticamente a única fonte de renda monetária, o suficiente para a subsistência do grupo. Ademais, as relações mercantis apresentam-se muito pouco desenvolvidas. Raramente se empregam trabalhadores assalariados. Em determinadas circunstâncias, como na colheita do café ou em obras de edificações, o suprimento de mão-deobra adicional é superado através do mutirão ou "ajuntamento". Em conseqüência, o número médio de trabalhadores por estabelecimento é relativamente pequeno, $6,3 \mathrm{em} 1920 .^{12}$

\footnotetext{
7 - Ib., p. 1302.3

8 - WAGEMANN, E. A colonizacão alemã no Espírito Santo. Rio de Janeiro, IBGE, 1949. p. 49.

9 - BISSOLI, Orestes. Memorias de um imigrante italiano. Vitória, FCAA, 1979. p. 19.

$10-1 B G E$, Recenseamento de 1920. Vol. III, $1^{\text {a }}$. parte.

$11-$ lb. p. 8-9.

$12-$ Ib., 3. Parte, p. XII, 5? Parte, p. XVIII
} 
Para os pesquisadores que visitaram o Espírito Santo no início deste século, da comparação da lavoura paulista com o café neste Estado emergiam dois contrastes principais: $19-$ a diferenca de tamanho das propriedades nos dois Estados; 2 ? - o café no Espírito Santo parecia estar "oculto" em comparação com o "mar de café" existente no interior paulista. A área média ocupada pelas plantações de café é significativamente mais reduzida no Espírito Santo em comparação com os outros Estados da região cafeeira. ${ }^{13}$ Além de pequenas, o caráter "invisível" dessas lavouras está associado também à sua localização, normalmente ocupando as encostas de morros, raramente as baixadas e os chapadões.

No entanto, essas pequenas produções estavam presentes em $78 \%$ dos estabelecimentos em 1920. Em São Paulo, os estabelecimentos rurais produtores de café significavam $26 \%$ do total, em Minas, $36 \%$, no Rio de Janeiro, $45 \%$ e no Paraná, ainda fora da região cafeeira, apenas $4 \% .^{14}$ A enorme difusão da cafeicultura no Estado permitiu que a produção capixaba crescesso o equivalente a 2,4 vezes entre as safras de 1902-3/1927-8, tornando-se o Espírito Santo o terceiro produtor no Brasil. ${ }^{15}$ O ritmo de crescimento seria ainda mais acentuado nos anos posteriores, com a incorporação do norte do Estado.

Além da política governamental, primeiro a do Império, depois a do governo estadual, outros fatores contribuíram para que a propriedade mantivesse seus limites relativamente pequenos no Espírito Santo, como, por exemplo, 1 - o relevo fortemente acidentado na serra capixaba, que dificulta o domínio sobre áreas muito extensas, dificultando também a incorporação de novas téc. nicas agrícolas, 2 - a baixa capitalização dos agricultores, o ponto mais vulnerável nas relações de troca do principal produto estadual: o café e 3 - o hábito prevalecente entre os imigrantes e seus descendentes de se estabelecer cada filho como proprietário, contribuindo ainda mais para o fracionamento da propriedade. Apesar da exploração de novas terras, para a terceira geração já não havia muito o que repartir. A primeira grande evasão ocorre em direção ao norte do Estado. A segunda, na década de 1960, em direção às cidades.

\footnotetext{
13 - Em 1920, a área média das plantações de café em São Paulo situava-se em torno de 48,20 ha, em Minas, 15,72 ha, no Rio de Janeiro, 18,06 e no Espírito Santo, 9,33 ha. Cf. TAUNAY, A.E. Historia do café no Brasil. Rio de Janeiro, DNC, 1939. Tomo II. Cap. LXIX, p 311.

14 - Cf. TAUNAY, Ioc cit., p. 314.

15 - DEPARTAMENTO NACIONAL DO CAFÉ. Anuário Estatístico, 1935 p. 7-8.
} 
A importância das migrações internas - do centro-sul para o norte do Estado - ocorridas com maior intensidade depois de 1930 pode ser aferida em dois pontos fundamentais: 10 - possibjlitou internamente, com recursos e populações próprias, a ocupação de aproximadamente a metade das terras estaduais, situadas ao norte do rio Doce; 2 ? - a incorporação econômica dessas terras se faz essencialmente da mesma forma como o processo colonizatório ocorrera no sul do Estado: pequena propriedade, empreendimento familiar, apoiado no consórcio da agricultura de subsistência com a produção de café destinado à exportação. Pelos dados censitários de 1940, era este Estado o que apresentava o menor índice de concentração fundiária do País. ${ }^{16}$

Desta forma o processo de ocupação das terras neste Estado ocorre de forma homogênea; as fronteiras demográfica e econômica se confundem. A infra-estrutura viária aparece como o resultado da própria expansão do café, e não o contrário. No movimento do café em direção ao oeste paulista, por exemplo, as estradas de ferro cumprem um papel fundamental. $O$ que normalmente ocorria é que a derrubada da mata e o plantio de novos pés passavam a ser estimulados pela chegada dos trilhos. ${ }^{17} \mathrm{O}$ movimento es. peculador com terras antecedia a própria lavoura.

\section{$4-$ SINTESE}

O café é o responsável pela inserção econômica do Espírito Santo no Brasil. Antes, não pôde esse Estado se aproveitar dos momentos favoráveis da economia de exportação, principalmente com relação ao açúcar. A ligação tardia do Espírito Santo à economia de exportação é compensada, no entanto, pelo potencial dos recursos locais: terra e mão-de-obra. Em meados do século passado, quase a totalidade do solo se achava inexplorado, época em que começa a ser direcionado para a Província um significativo fluxo de imigrantes europeus, que se ocuparão primordialmente da cultura do café.

Nas regiões vizinhas às Províncias de Minas Gerais e do Rio de Janeiro, o café se desenvolve em moldes tradicionalmente conhecidos: a grande fazenda escravista. Coexistem, no entanto, produção

16 - Cf. CÂMARA, Lourival. A concentração da propriedade agrária no Brasil.Boletim Geográfico, Rio de Janeiro, 7(77):516-28, ago "1949. p. 519.

17 - CASTRO, A.B. de. Op. cit..p. 62. 
escravista e pequena propriedade até fins do século passado. Com a abolição da escravatura e a crise de preços em fins dos anos noventa, "(...) as grandes fazendas desapareceram no Estado". ${ }^{8}$ Cultivavam o café principalmente os imigrantes italianos e alemães, quase todos dispondo de lotes de terra. ${ }^{19}$

O período compreendido entre a última década do século XIX e a terceira década deste século é o período de consolidação da pequena propriedade como unidade de produção no cultivo do café no Estado do Espírito Santo. Sem contar com correntes imigratórias diretamente do exterior, a incorporação econômica do norte do Estado será reservada às migrações internas, cujos resultados principais são duas faces do mesmo processo: difusão da pequena propriedade e expansão cafeeira, o que permitiria ao Espírito Santo chegar à década de 1940 produzindo o equivalente a $15 \%$ do café brasileiro.

\section{5 - SUGESTŌES}

Este trabalho, essencialmente indicativo, não aborda problemas que requerem maior reflexão. Entre outros, sugere-se os seguintes:

1 - E provável que as grandes lavouras de café no Espírito Santo, predominantes até a década de 1880, tenham sua importância superestimada, uma vez que as grandes dimensões desses empreendimentos não eram acompanhadas por grandes plantações de café. Neste sentido, os fazendeiros do sul do Estado seriam muito mais latifundiários do que produtores de café.

2 - $O$ verdadeiro caráter da imigração estrangeira não fica ex. plícito. Se o objetivo era o de constituir uma agricultura complementar, o café teria sido uma fatalidade que deu certo.

3- 0 comércio do café capixaba era intermediado por atacadistas que o revendiam aos comissários estabelecidos em Vitória, ligados a grandes empresas exportadoras com sede no Rio de Janeiro. No início do circuito comercial estava o agricultor, que normalmente vendia o café "em coco", transformando-se no grande deficitário na repartição dos ganhos desse produto. Desta forma, estima-se que grande parte do excedente do café tenha se transferido,

18 - TORRES FILHO, A.E.M. O Espirito Santo e seu desenvolvimento econômico. Rio de Janeiro, Pimenta de Mello \& Cia., 1913. p. 111.

19 - Ib., p. 115 . 
via comércio, para fora do Espírito Santo. Este foi, talvez, o maior obstáculo para o surgimento de atividades industriais no Estado.

\section{BIBLIOGRAFIA SELECIONADA SOBRE O ASSUNTO}

AGUIAR, Audifax. O cafe no estado do Espírito Santo. Rio de Janeiro, Alba Oficinas Gráficas, 1932. $56 \mathrm{p}$.

FERREIRA DE ALMADA, Vilma Paraiso. A escravidão na história econômico-social do Espirito Santo - 1850/1888. Niterói, Universidade Federal Fluminense, 1981. Dissert. Mestr. História. $240 \mathrm{p}$.

BISSOLI, Orestes. Memórias de um imigrante italiano. Vitória, FCAA, 1979. (Estudos Capixabas, 1.) 254p.

BITTENCOURT, Gabriel Augusto de Mello. Esforço industrial na República do café: o caso do Espirito Santo - 1889/1930. Vitória, FCAA, 1982. 155 p.

CELIN, José Lazaro. Migração européia, expansão cafeeira e o nascimento da pequena propriedade no Espírito Santo. Porto Alegre, Universidade Federal do Rio Grande do Sul, 1984. Dissert. Mestr. Economia. 330 p.

COSTA, Luciana Osório. A colônia do Rio Novo - 1854/1880. São Paulo, Universidade de São Paulo, 1981. Dissert. Mestr. História. $116 \mathrm{p}$.

GIEMSA, G.B. \& NAUCK, E.G. Uma viagem de estudos ao Espírito Santo. Boletim Geografico. Rio de Janeiro, 8(88):451-70, jul. 1950; 8(89):560-75, ago. 1950; 8(90): 653-701, set. 1950.

OLIVEIRA, José Teixeira de. História do estado do Espirito Santo. 2.ed. Vitória, FCES, 1975, $596 \mathrm{p}$.

PORTAL, Maria da Glória Alves. Análise de documentos concernentes à propriedade ru ral na primeira colônia teuta em terra capixaba - 1847/1920. In: VIll Simpósio Nacional dos Professores Universitários de História. Anais. São Paulo, 1976, p. 551 77.

ROCHA, Haroldo Correa \& COSSETTI, Maria da Penha (Coord.). Dinâmica cafeeira e constituições de indústrias no Espírito Santo -..1850/1930. Vitória, IJSN/GERES/ UFPES, 1983.

ROCHE, Jean. A colonização alemă no Espirito Santo. São Paulo, Difel/USP, 1968. 387 p.

SIQUEIRA, Maria da Penha. O desenvolvimento do Porto de Vitoria - 1870/1940. Florianópolis, UFSC, 1980. Dissert. Mestr. História. 137 p.

TORRES FILHO, Arthur E. Magarinos. O Espirito Santo e seu desenvolvimento economico. Rio de Janeiro, Pimenta de Mello \& Cia., 1913. 493 p.

WAGEMANN, Ernst. A colonização alema no Esplrito Santo. Rio de Janeiro, IBGE, 1949. $104 \mathrm{p}$. 